\title{
18. PHOSPHATE CONTENT OF SEDIMENTS FROM DEEP-SEA SITES 259 TO 263, EASTERN INDIAN OCEAN ${ }^{1}$
}

\author{
Peter J. Cook, Bureau of Mineral Resources, Geology and Geophysics, Canberra, Australia
}

\begin{abstract}
Phosphate determinations carried out on material from Sites 259 to 263 , in the Eastern Indian Ocean, revealed the presence of several phosphate maxima, particularly in the Mesozoic. A thin high-grade phosphorite was intercepted at Site 259. In general, the Cenozoic calcareous oozes are more phosphatic than the Mesozoic noncalcareous sediments. Abundance of biogenic (generally calcareous) material has a significant effect on the amount of phosphate present. Variation in the rate of sedimentation is also believed to be important in determining the phosphate content of sediments. Some phosphate peaks may be associated with important time breaks.
\end{abstract}

\section{INTRODUCTION}

Phosphorus is one of the most important nutrients found in the oceans. Its abundance in the water column is reflected both in the phosphatic and biotic content of the bottom sediments. Despite its importance, little systematic work has previously been undertaken on the phosphorus content of sediments obtained as part of the Deep Sea Drilling Project. In order to help remedy this deficiency, a sample was taken for phosphate analysis from every core-section obtained from the five holes drilled on Leg 27 (Figure 1).

A total of 680 samples was dried, crushed, and colorimetrically analyzed for phosphate at the Australian Mineral Development Laboratories, using the molybdenum blue method.

\section{RESULTS}

The phosphate values from the five sites are shown in Figures 2 and 3 . The $\mathrm{P}_{2} \mathrm{O}_{5}$ content is generally in the range of 700 to $1500 \mathrm{ppm}$, but is less than $200 \mathrm{ppm}$ in a few samples. The maximum value was $22.4 \% \mathrm{P}_{2} \mathrm{O}_{5}$ at Site 259, at the top of sedimentary Unit IV. Mean phosphorus contents for Mesozoic and Cenozoic sediments are summarized in Table 1. If the single high value of $22.4 \%$ is excluded, the $\mathrm{P}_{2} \mathrm{O}_{5}$ content of the Mesozoic sediments is similar at each site and averages $1000 \mathrm{ppm}$. The $\mathrm{P}_{2} \mathrm{O}_{5}$ content of the Cenozoic sediments shows greater variation between holes, and the mean $\mathrm{P}_{2} \mathrm{O}_{5}$ value of $1530 \mathrm{ppm}$ is somewhat higher than the average Mesozoic $\mathrm{P}_{2} \mathrm{O}_{5}$ content.

Repeat analyses on 10 samples indicated a precision of $\pm 3.8 \%$. Accuracy is claimed by the laboratory to be about $\pm 5 \%$, and the results reported here compared with values obtained by El Wakeel and Riley (1961) on deep-sea sediments and support this level of accuracy. It should perhaps be pointed out that the sampling technique involved taking a small plug of material, with a diameter of approximately $2.5 \mathrm{~cm}$, every 1.5 meters.

'Published with the permission of the Director, Bureau of Mineral Resources, Geology and Geophysics, Canberra, Australia.

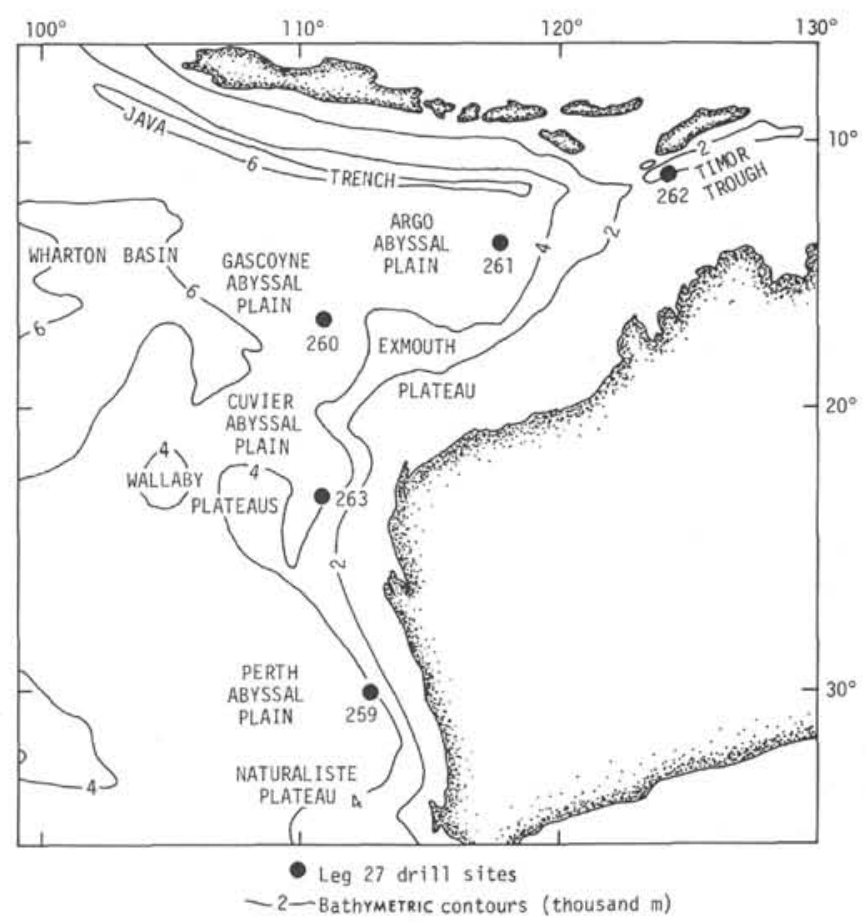

Figure 1. Locality map.

Consequently, despite the fact that a large number of samples were obtained, only a small percentage of the total sequence was in fact sampled. It is therefore probable that some phosphate peaks were missed.

The sample containing $22.4 \% \mathrm{P}_{2} \mathrm{O}_{5}$ was examined in detail. X-ray diffraction analysis revealed that it is composed primarily of carbonate fluorapatite. In thin section it consists, for the most part, of a structureless groundmass of cryptocrystalline collophane. Dark collophane pellets showing sharp margins, and "blebs" with diffuse margins, are scattered throughout (Figure 4). It is uncertain whether the darker coloration of the pellets is due to staining by organic material or by iron oxides. Some poorly defined apatite hexagons are present in vugs. Small, high-relief cubic crystals are also present in vugs; they could not be positively identified in 


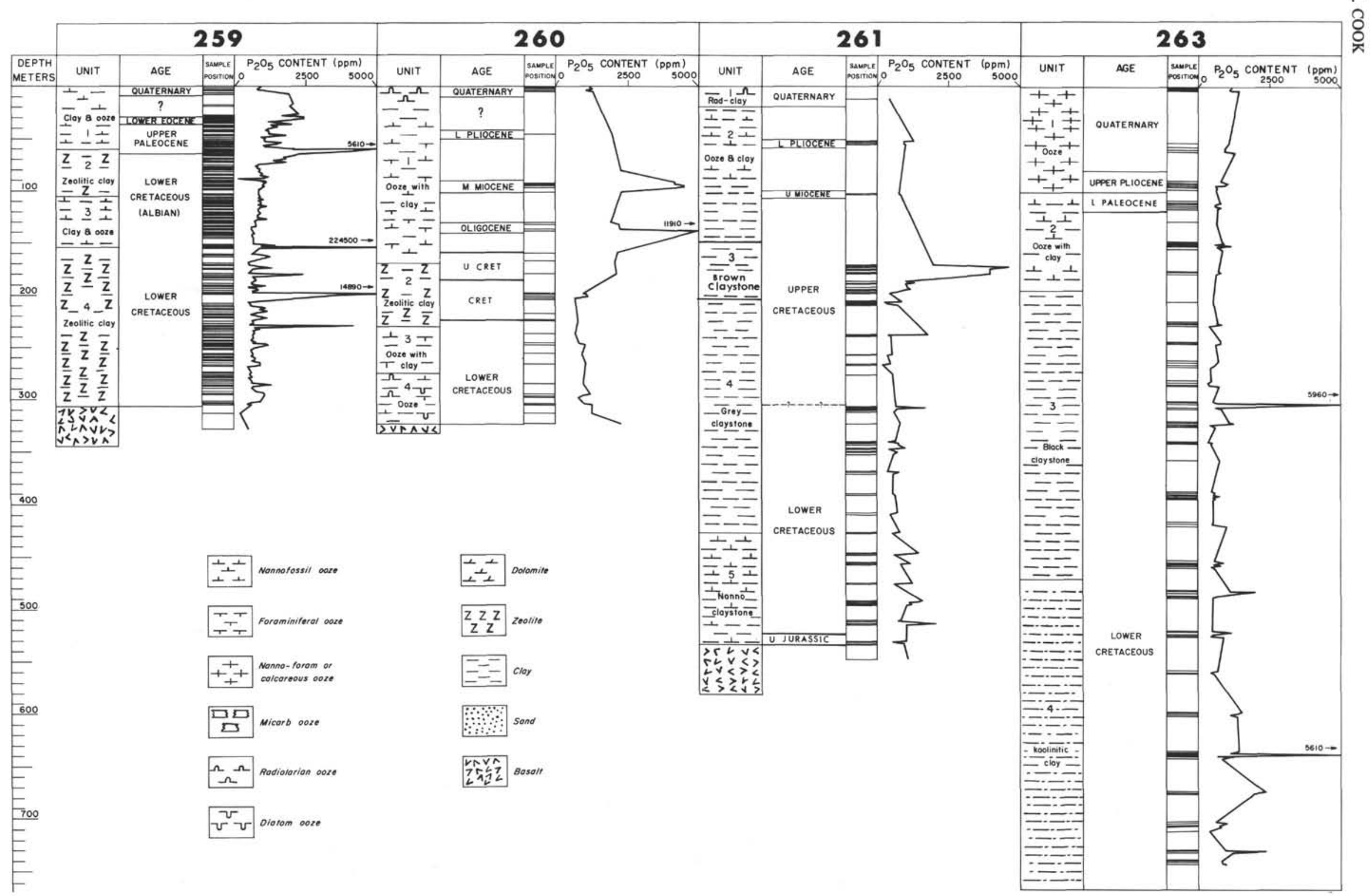

Figure 2. Vertical variation in phosphorite content of the Mesozoic-Cenozoic sediments encountered at Sites 259, 260, 261, and 263. 


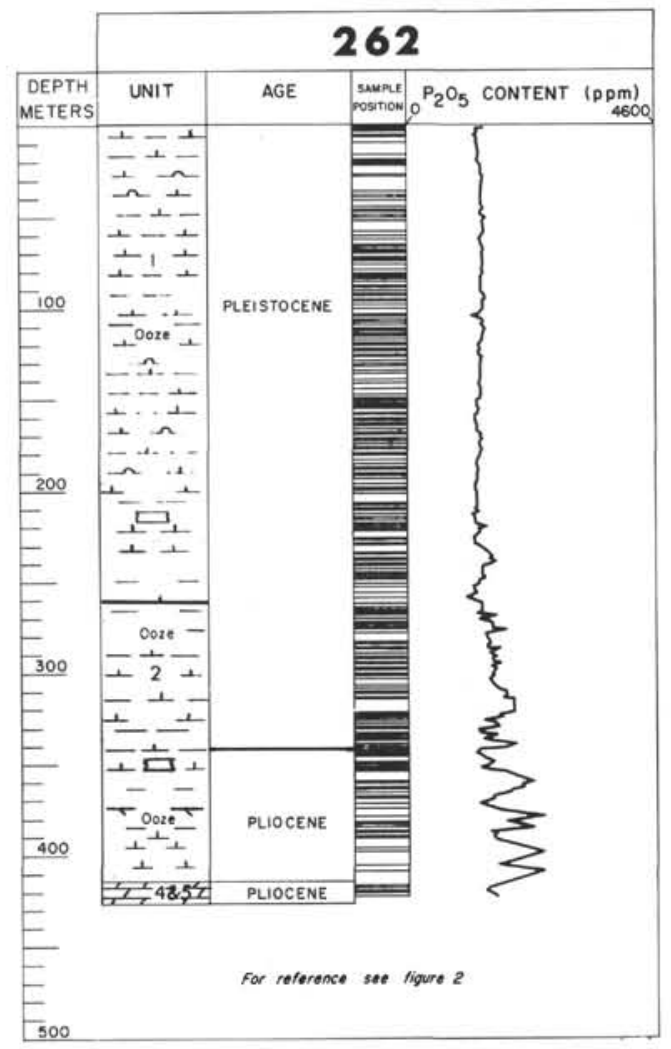

Figure 3. Vertical variation in phosphate content of the Plio-Pleistocene sediments encountered at Site 262.

thin section but may be fluorite. Phosphatized fragments of coccoliths, radiolarian spines, and ?foraminiferal fragments are scattered sparsely throughout the collophane groundmass. A small patch of ?glauconite is present; there are also scattered silt-size quartz grains, some showing marginal replacement by apatite.

TABLE 1

$\mathrm{P}_{2} \mathrm{O}_{5}$ Content of Leg 27 and Other Pelagic Sediments

\begin{tabular}{ccr}
\hline & \multicolumn{2}{c}{$\begin{array}{c}\text { Phosphate Content } \\
\left(\mathrm{ppm}_{2} \mathrm{O}_{5}\right)\end{array}$} \\
Site & Mesozoic & Cenozoic \\
\hline 259 & $928^{\mathrm{a}}$ & 1395 \\
260 & 985 & 3047 \\
261 & 1127 & 903 \\
262 & - & 1338 \\
263 & 960 & 974 \\
Mean Value & 1001 & 1530 \\
& & 1550 \\
Mean $\mathrm{P}_{2} \mathrm{O}_{5}$ content & Calcareous & 1400 \\
of pelagic sediments & Argillaceous & 2700 \\
& Siliceous & 1600 \\
\hline
\end{tabular}

${ }^{\mathrm{a}}$ Excluding the highly phosphatic sample containing $22.4 \% \mathrm{P}_{2} \mathrm{O}_{5}$. If this sample is included mean Mesozoic value for Site 259 is $2410 \mathrm{ppm} \mathrm{P}_{2} \mathrm{O}_{5}$.

${ }^{\mathrm{b}}$ After El Wakeel and Riley (1961).

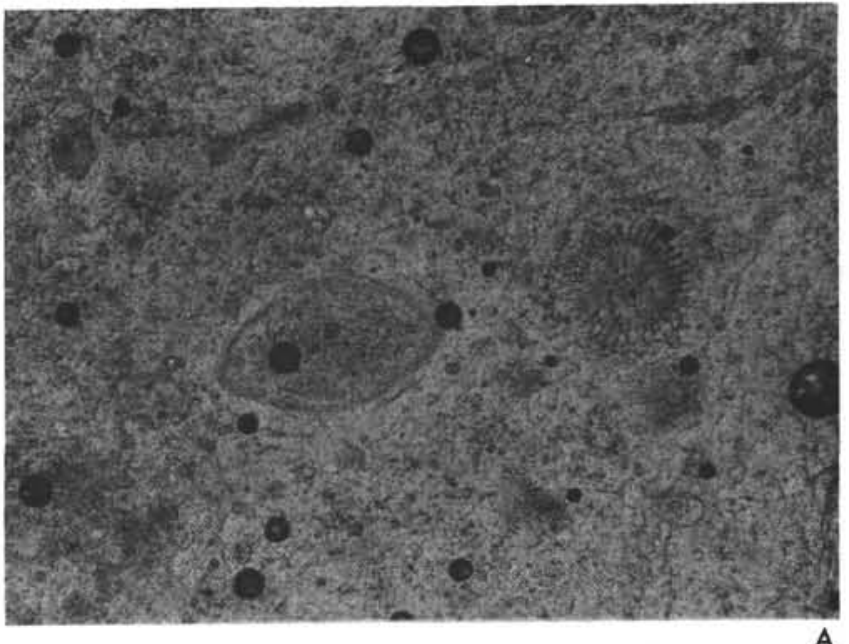

A

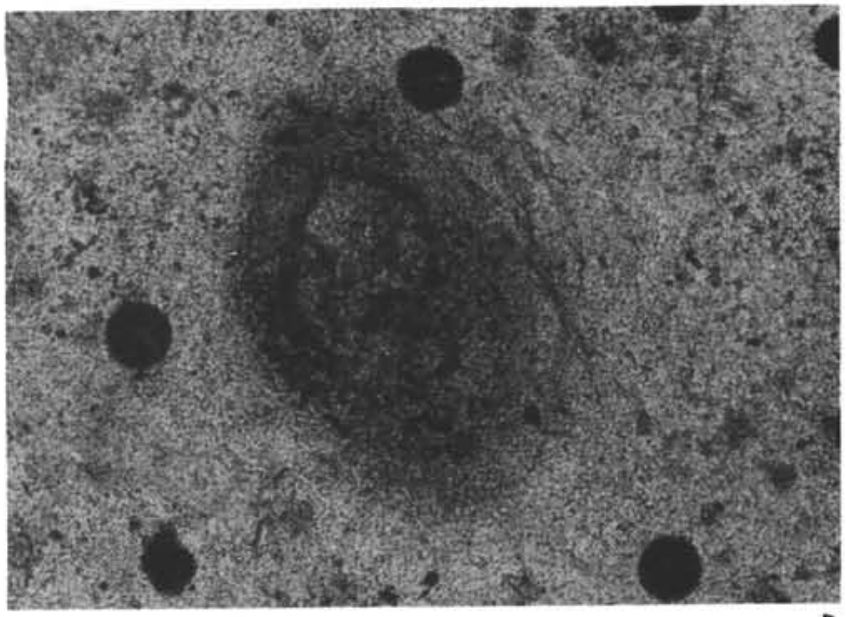

B

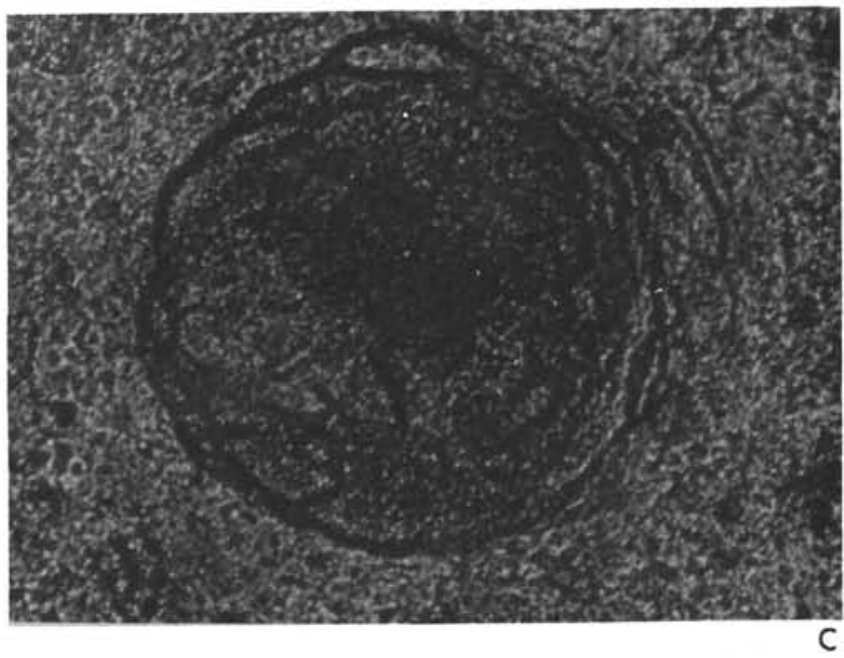

Figure 4. Photomicrographs of the phosphorite from Site 262. (Sample 17-4, 29-31 cm). (a) Rounded phosphate pellet with well-defined margins. Ordinary light. Scale represents $0.10 \mathrm{~mm}$. (b) Poorly defined phosphate "bleb" with a diffuse margin. Ordinary light. Scale represents $0.15 \mathrm{~mm}$. (c) Structureless mass of collophane with some included microfossils. Scale represents $4.0 \mathrm{~mm}$. 
With the exception of fish fragments, no other example of apatite or collophane was noted in thin sections or smear mounts or detected by X-ray diffraction.

\section{DISCUSSION}

The phosphate content of sediments is influenced considerably by the phosphate content of the adjacent waters, whether oceanic or pore water. Other important controlling factors include the rate of sedimentation, the biota, and the lithology of the sediments. In some circumstances the phosphate content of a sediment comes primarily from allochthonous apatite and collophane reworked from some older unit, such as Adams et al. (1961) have described from the Cenozoic of Maryland. However, it is unlikely that allochthonous sources of phosphate make any important contribution to abyssal zone sediments, under most circumstances. Much discussion on the geochemistry of phosphorus in sediments, and particularly phosphorites, has revolved around the question of whether the phosphate is a primary precipitate or a secondary replacement deposit (see Kazakov, 1937; Dietz et al., 1942; Emigh, 1958). Most of these arguments have little relevance to the Leg 27 sediments which are not phosphorites, with the notable exception of the sediment on the Unit III/Unit IV boundary at Site 259 . This phosphorite, which is described above, is lithologically unlike the well-known pelletal phosphorites of, for instance, the Phosphoria Formation of the western United States. It is somewhat similar to the collophane mudstones or microsphorites of Riggs and Freas (1965) and also has some features in common with phoscretes (Cook, 1972). All these finegrained phosphorites are believed to have formed under very shallow water or in some circumstances, subaerial conditions, but it is unlikely that the fine-grained phosphorite at Site 259 formed under such conditions. In thin section there is evidence that the phosphorite is, in part, a replacement deposit. The nature of the sediment before phosphatization is uncertain. Included fossil fragments (Figure 4) suggest it was in part calcareous; however, both siliceous and argillaceous sediments also undergo phosphatization under marine conditions. The depth of seawater at the time of deposition is unknown, but it was probably considerably shallower than the present-day water depth. Phosphatization of sediments can take place in water with a low $\mathrm{P}_{2} \mathrm{O}_{5}$ concentration if the rate of deposition is sufficiently slow. Consequently, it may not be necessary to invoke high phosphate values in the water, such as those encountered during upwelling, to account for the Site 259 phosphorite. It seems probable that this phosphorite formed by early diagenetic phosphatization of calcareous and argillaceous sediments, at a time when a slow rate of deposition prevailed. Although there is only one phosphorite known from the Leg 27 drill holes, there are nevertheless marked vertical variations in the phosphate content in the drill holes.

The background phosphate level is higher in the Cenozoic calcareous oozes than in the Mesozoic siliceous and argillaceous clays. It is likely that this Cenozoic/Mesozoic difference results primarily from the change in lithology between the sediments of these two eras. Foraminifera and other organisms, which contribute a significant percentage of material to the oozes, incorporate some phosphate in their tests as a result of metabolic processes. In addition, calcareous material is readily phosphatized at the sediment-water interface even in aqueous solutions with a comparatively low phosphate content (Ames, 1959). As a result of these primary and early diagenetic processes, the Cenozoic calcareous sediments are enriched in phosphate relative to the predominantly noncalcareous Mesozoic sediments.

There is also some evidence of late diagenetic phosphatization within the Cenozoic column, particularly at Site 262. This and other diagenetic features of Site 262 are discussed by the writer in a subsequent chapter in this volume. It appears that the downward increase in phosphate content at Site 262 (Figure 3) may be a function of late-stage diagenetic phosphatization processes, possibly associated with dolomitization. The writer has previously found that phosphatization may in some circumstances be related to dolomitization in the shallow marine environment. It appears that this same correlation may hold in deep-sea sediments of the Timor Trough, with the dolomite content as determined by Xray diffraction showing a good positive correlation with the $\mathrm{P}_{2} \mathrm{O}_{5}$ content. There is also strong evidence linking high $\mathrm{P}_{2} \mathrm{O}_{5}$ values in interstitial waters with a high alkalinity, though the reason for this interrelationship is not known.

Figure 2 shows that there are a number of phosphate peaks within the Mesozoic (Jurassic-Cretaceous) sequence. At all four sites where Mesozoic rocks were penetrated, the sediments are uniform clays and claystones. Phosphate maxima do not appear to be related to an influx of calcareous beds. Also the magnitude of the peaks is considerably in excess of that which would result solely from the influx of calcareous ooze. Some peaks may represent a fortuitous event such as the incorporation of fragments of whale bones or shark teeth into the abyssal zone sediments. Late diagenesis is unlikely to produce peaks of the type evident in Figure 2, but would, instead, give a regular vertical trend of increasing (e.g., Figure 3 ) or, in some circumstances, decreasing phosphate content. Sheldon (1964) has pointed out that paleolatitude is an important limiting parameter for the formation of phosphorites.

Latitudinal changes in response to sea-floor spreading could conceivably produce a change in the phosphate content of abyssal zone sediments. Figure 5 shows the change in phosphate content in deep Indian Ocean waters but the changes are small. Similarly, changes in bathymetry could conceivably alter the phosphate content of sediments. It is apparent from Figure 6 that there is a phosphate maximum in the water column at about 1000 meters, but below this depth the phosphate rapidly stabilizes at about $2.7 \mu \mathrm{g}$ atom P/1. Again the magnitude of the phosphate changes likely to be induced by bathymetric variation appears to be insufficient to account for the observed phosphate maxima in the sediment column.

Oceanic upwelling is believed to be an important mechanism for the localization and concentration of phosphate (Kazakov, 1937; Baturin et al., 1972). Upwelling has the effect of bringing cold nutrient-rich water to the surface, particularly on the west coast of continents, 


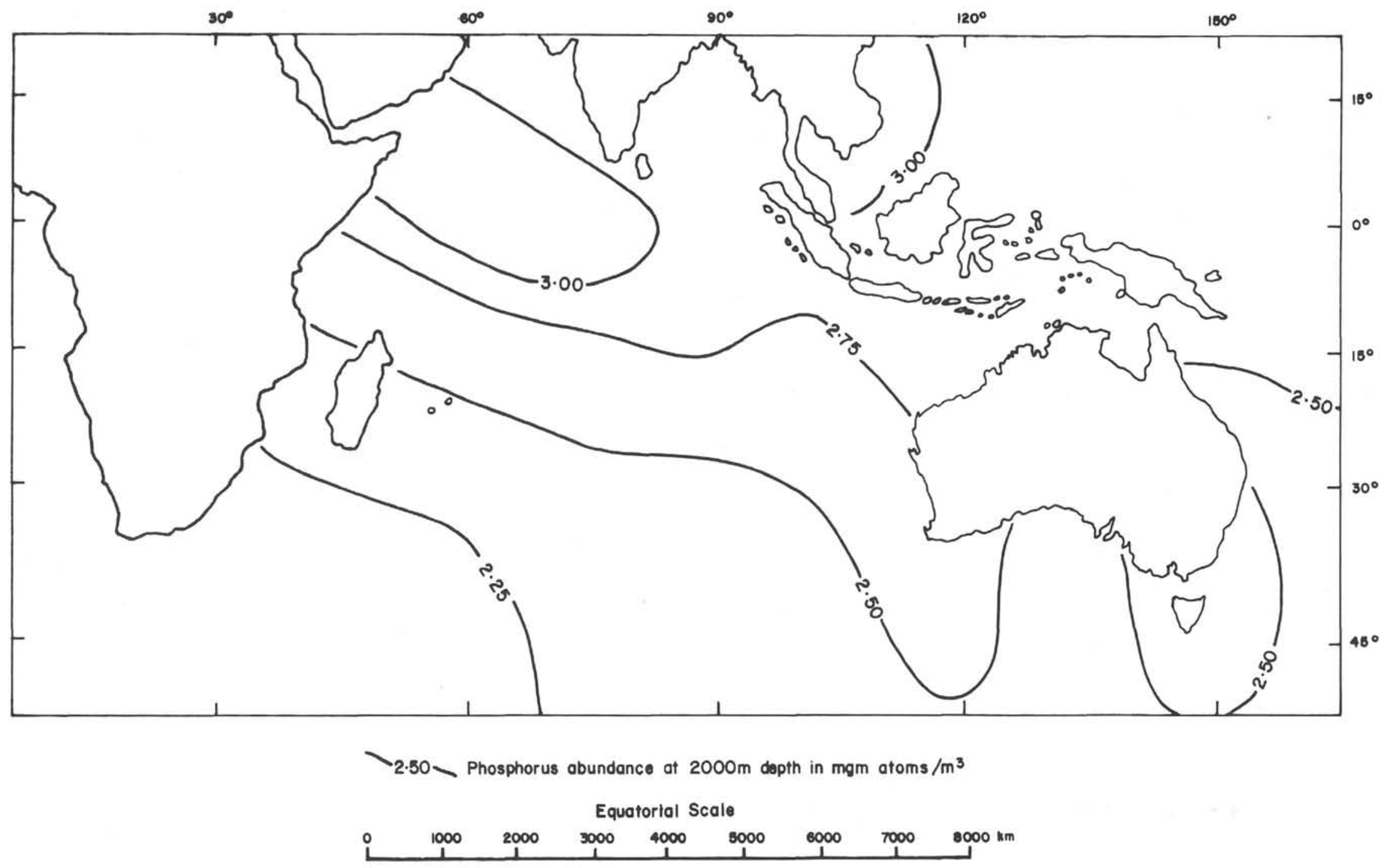

Figure 5. Phosphorus content of Indian Ocean waters at a depth of 2000 meters (after Redfield, 1958).

藏 


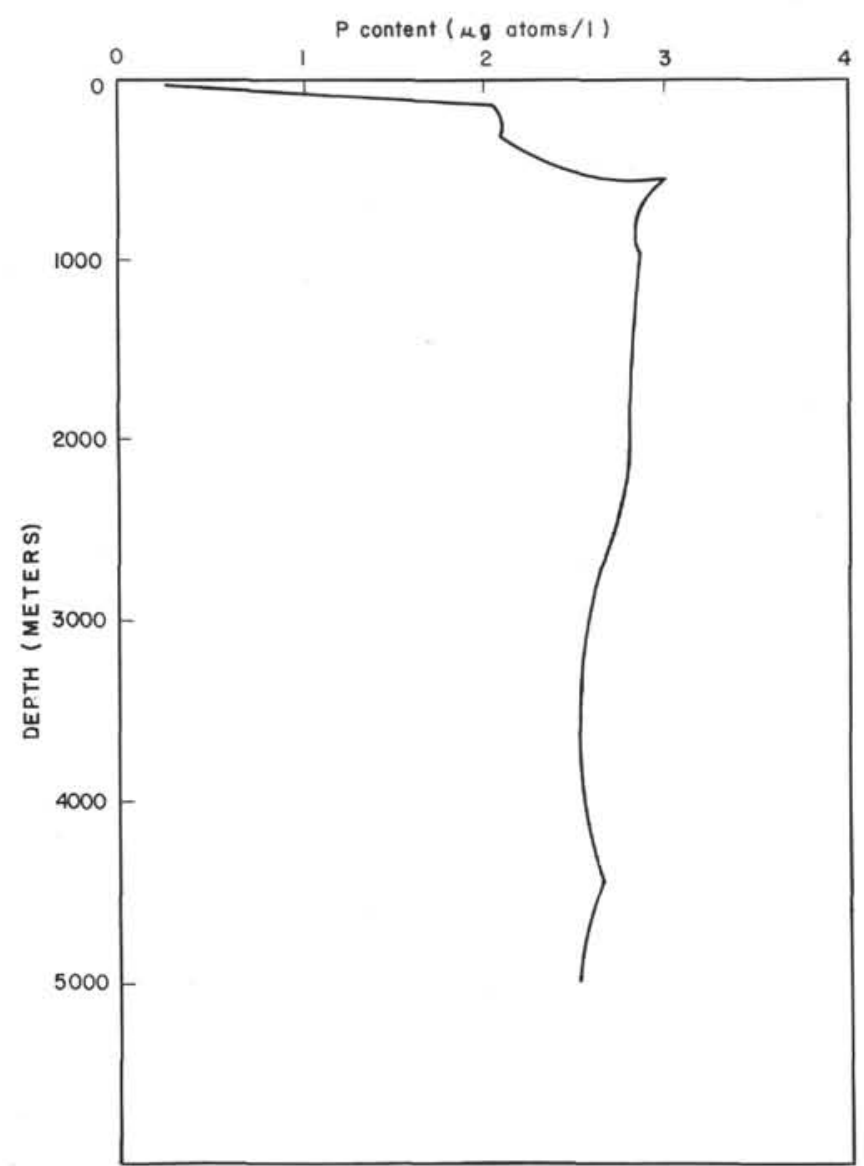

Figure 6. Vertical distribution of phosphorus in the Indian Ocean (after Bruneau et al., 1953). Station location $4^{\circ} 47^{\prime} \mathrm{S}, 88^{\circ} 18^{\prime} \mathrm{E}$.

e.g., off Peru. In some areas, it is a comparatively shallow process with, for instance, upwelling only affecting the top 200 meters of the ocean off Southern California. It is evident from Figure 6 that upwelling from deep ocean water (particularly of that below $500 \mathrm{~m}$ ) would result in the influx of phosphate-rich waters into the euphotic zone. Intermixing of water below 500 meters will have no appreciable effect because of the essentially uniform phosphate profile below that depth. Even upwelling into the shallow euphotic zone can produce higher phosphate levels in abyssal sediments because of an increased influx of dead biogenic material. However, at least part of the Mesozoic section is believed to be of comparatively shallow-water origin, where localized, fairly near-shore upwelling may have had some influence on the phosphate content of sediments, particularly a high-grade phosphorite such as that encountered at Site 259.

It is likely that some upwelling occurs off the west Australian coast because of its position on the west side of a continent. However, Rochford (1967) points out that the upwelling is relatively minor and does not occur east of about long $110^{\circ} \mathrm{E}$. It is possible that some upwelling has occurred at various times since the development of the Indian Ocean in the Late Jurassic-Early Cretaceous. This is supported by the presence of Cretaceous phosphorites in the Toolangi Calcilutite in the onshore section of the Carnarvon Basin.
It is unnecessary to invoke an upwelling origin for all phosphatic concentrations, for such concentrations also commonly occur on unconformity and disconformity surfaces in shallow marine sediments. In the absence of subaerial weathering, this hiatus-phosphate association results primarily from the lack of sediments which would otherwise dilute the phosphatic sediments forming at, or just below, the sediment-water interface. At Site 259 , a prominent phosphate peak is located on the Albian-Paleocene hiatus, a time break of about 35 m.y. An additional phosphate peak is located on the marked lithologic change between Units III and IV, which may also represent a hiatus. It is uncertain whether a hiatus can be invoked for other phosphate peaks as the chronostratigraphic resolution is generally insufficient to allow correlations between phosphate peaks and disconformities. However, the lack of a reasonable alternative makes a hiatus-phosphate association the most attractive hypothesis at this stage.

\section{CONCLUSIONS}

1. Considerable variation in phosphate content occurs in the sediments encountered in Leg 27 drilling; a thin Cretaceous phosphorite is present at Site 259 .

2 . The Cenozoic calcareous oozes are more phosphatic than the Mesozoic argillaceous and siliceous clays. This difference is believed to result primarily from the abundance of biogenic material in the Cenozoic sequence.

3. Some diagenetic phosphatization of calcareous sediments, possibly associated with dolomitization, may have taken place in the Cenozoic sediments at Site 262.

4. Several prominent phosphate maxima are present in the Mesozoic sequence. Although some could perhaps be related to oceanic upwelling, there is no evidence for this. There is evidence that at least some of the peaks may be related to major time breaks within the Mesozoic. Most of the phosphate peaks may ultimately prove to be associated with disconformity surfaces.

\section{REFERENCES}

Adams, J. K., Groot, J. J., and Hiller, N. W., 1961. Phosphatic pebbles from the Brightsea Formation of Maryland: J. Sediment. Petrol, v. 31, p. 546.

Ames, L. L., Jr., 1959. The genesis of carbonate apatites: Econ. Geol., v. 54 , p. $29-41$.

Baturin, G. N., Merkulova, K. I., and Chalov, P. I., 1972. Radiometric evidence for recent formation of phosphatic nodules in marine shelf sediments: Marine Geol., v. 13, p. 37.

Bruneau, L., Jerlov, N. G., and Koczy, F. F., 1953. Physical and chemical methods, Appendix Table 1: Swedish DeepSea Exped. Rept., v. 3, p. 99.

Cook, P. J., 1972. Petrology and geochemistry of the phosphate deposits of northwest Queensland: Econ. Geol., v. 67, p. 1193.

Dietz, R. S., Emery, K. O., and Shepard, F. P., 1942. Phosphorite deposits on the sea floor off southern California: Geol. Soc. Am. Bull., v. 53, p. 815.

El Wakeel, S. K. and Riley, J. P., 1961. Chemical and mineralogical studies of deep-sea sediments: Geochim. Cosmochim. Acta, v. 25, p. 110. 
Emigh, G. D., 1958. The petrography, mineralogy and origin of phosphate pellets in the Phosphoria Formation: Idaho Bur. Mines Pamphlet 114.

Kazakov, A. V., 1937. The phosphorite facies and the genesis of phosphorites: Internatl. Geol. Cong., 17th, Leningrad, p. 95.

Redfield, A. C., 1958. The biological control of chemical factors in the environment: Am. J. Sci., v. 56, p. 205.
Riggs, S. R. and Freas, D. H., 1965. Stratigraphy and sedimentation of phosphate in the central Florida phosphate district: Am. Inst. Min. Eng. Ann. Mtg., Section H84.

Rochford, D. J., 1967. The phosphate levels of the major surface currents of the Indian Ocean: Australian J. Mar. Freshwater Res., v. 18, p. 1.

Sheldon, R. P., 1964. Palaeolatitudinal and palaeogeographic distribution of phosphorite: U.S. Geol. Surv. Prof. Paper 501-C, p. 106. 